\title{
Meeting, Knowing, and Affirming Spanish-speaking Immigrant Families Through Successful Culturally Responsive Family Engagement
}

\author{
María L. Gabriel, \\ Poudre School District \\ Fort Collins, $\mathrm{CO}$ \\ Kevin C. Roxas, \\ Western Washington University \\ Bellingham, WA \\ Kent Becker \\ Saybrook University \\ Oakland, $C A$
}

\begin{abstract}
School districts and community agencies continue to support families with family involvement and engagement opportunities, but we question the methods utilized and the gap between the ideological beliefs and the beliefs of the families being served. In this article, we analyze data from one strand of a year-long study to explain and demonstrate the successful use of culturally responsive pedagogy when applied to the development of school-family partnerships with families from immigrant backgrounds. Six Spanish-speaking parent participants in the study shared their perspectives through Photovoice, a collaborative research method. The families shared intimate descriptions of the strengths of their families, their expectations for their children in school, their own experiences with schools, and what they want educators to know about them and their families. Given the findings, we conclude the article by asserting that educational leaders must rethink traditional models, methods, and strategies of family engagement and seek to be more inclusive in engaging a broader section of families in their partnering efforts to meet, know, and affirm Spanish-speaking immigrant family members.
\end{abstract}


Meeting, Knowing, and Affirming Spanish-speaking Immigrant Families

\section{Introduction}

"We would like teachers to know that we came to this country to better ourselves and to help our children get ahead." -Luis

This statement by a Mexican immigrant parent declares an important message that often goes unheard, unrecognized, or is undervalued because schools offer family engagement efforts that are not culturally responsive. Schools and communities around the nation have escalated efforts to provide family engagement. Educators are valuing the perspectives of parents, and that is positive. Yet, the methods and strategies used to engage families are often created based on the ideological belief systems of the main leadership of family engagement teams, often constituted by people who are members of the White middle or upper class. This gap in method and strategy often negates the stories of culturally and linguistically diverse families.

While the demographics of students are shifting in classrooms to increasingly become more heterogeneous, teachers in U.S. schools remain largely White (National Collaborative on Diversity in the Teaching Force, 2004). This demographic reality is true for most leadership positions in schools. The disjuncture between a diverse student population and a homogenous teaching force has created a cultural gap between teachers and their students. The cultural discontinuity of White teachers working with students from diverse cultural backgrounds (Davis, 2007; Howard, 2006; Landsman \& Lewis, 2006; Viadero, 1996) often creates a gap in understanding the significant impacts of bias. In the school district where this study took place, 95\% of the teachers were White, while $75 \%$ of the student population was White. Four percent of teachers were Latina/o and served a student population of $18 \%$ Latina/o students. The lack of representation of Latina/o educators to work with a growing Latina/o student and parent population within the district was clear. The increasing enrollment of immigrant students throughout the district pointed to an important need by teachers, counselors, administrators, and support staff within the district to gain a better understanding of the backgrounds, experiences, and cultures of these students and their families. The voices of immigrant students and parents are often unheard, unnoticed, or unsolicited, but increasing cross-cultural understanding, awareness, and sensitivity is a necessary step in creating more inclusive school communities.

This article reports on one strand of findings from a larger year-long research project which used the Photovoice method (Gagne, Bowers, Russinova, Bloch, \& McNamara, 2010; Guerrero, A., \& Tinkler, 2010), seeking to shed light on the important voices and perspectives of Spanishspeaking immigrant families in school communities. This article begins with a brief literature review related to culturally responsive pedagogy and culturally responsive family engagement and continues with methods and findings from the study. We conclude the article with a discussion of how this research can be used to impact family and school partnerships with immigrant families.

\section{Literature Review}

\section{Culturally Responsive Pedagogy}

Cultural competence is defined as "systems, agencies, and practitioners with the capacity to respond to the unique needs of populations whose cultures are different than what might be called "dominant" or "mainstream" American" (Cross, Bazron, Dennis, \& Isaacs, 1989, p. 18). The practice of cultural competence requires "the acquisition of knowledge, skills, attitudes, and values that will enable individuals, organizations, and societal institutions to respond effectively 
to a diverse society" (Lockhart \& Mitchell, 2010, p. 5). The need for cultural competence has been advocated for by professionals in the fields of mental health, domestic violence, nursing, social work, and later in education (Cross et al., 1989; Hess, Lanig, \& Vaughan, 2007; Lindsey, Nuri Robins, \& Terrell, 2003, 2009; Lockhart \& Danis, 2010; Wells, 2000).

Much of the work around culturally responsive educational practices initially developed in the 1990s after mental health professionals introduced a cultural competence model to address identified cultural differences impeding health care delivery (Cross et al., 1989). For example, researchers studied how people of color had "languages, customs, values, lifestyles, beliefs, and behaviors that differ" from those of their health care providers and that specific needs for improvement in service delivery were inferred by practitioners rather than understood (Wells, 2000, p. 190). Researchers also found that disparities in treatment were problematic in efforts to better serve diverse populations (Cross et al., 1989). The cultural competence model was adapted for use in the field of education as the demographics of students and their families continued to shift in schools in the U.S. (Lindsey et al., 2003). To assist in differentiating between the healthcare field and the field of education, Villegas and Lucas (2002) proposed six curricula strands to prepare culturally responsive teachers:

Such a [culturally responsive] teacher (a) is socioculturally conscious, that is, recognizes that there are multiple ways of perceiving reality and that these ways are influenced by one's location in the social order; (b) has affirming views of students from diverse backgrounds, seeing resources for learning in all students rather than viewing differences as problems to overcome; (c) sees himself or herself as both responsible for and capable of bringing about educational change that will make schools more responsive to all students; (d) understands how learners construct knowledge and is capable of promoting learners' knowledge construction; (e) knows about the lives of his or her students; and (f) uses his or her knowledge about students' lives to design instruction that builds on what they already know while stretching them beyond the familiar. (p. 21)

Culturally responsive teaching includes incorporating multiple aspects of students' cultural experiences as part of their learning (Gay, 2010; Ladson-Billings, 2009; Trumbull \& Pacheco, 2005). In this approach to teaching, children learn about themselves and the world around them within the context of culture, but they also begin to learn how culture impacts teaching and learning. While many educators across the United States are working to incorporate culturally responsive teaching into their classrooms, there has also been an increasing interest in creating culturally responsive family engagement within classrooms and schools as a means to foster higher levels of parent/family engagement in schools, and thereby increasing students' success in schools (Henderson \& Mapp, 2002; Cooper, Riehl, \& Hasan, 2010).

\section{Culturally Responsive Family Engagement}

For many years schools have mainly conceptualized parental involvement in schools as parents volunteering for parent committees such as the Parent Teacher Association (PTA) or in various forms of parent fundraising committees such as school bake sales and jog-a-thons. Unfortunately, the membership and leadership of most parent committees are often members of the dominant group. The parent committees often do not mirror the demographics of the larger school population. Parents who are from immigrant backgrounds, English language learners, or of 
lower socio-economic status are not often represented in these committees and do not always feel welcome to join these groups.

However, within the last decade, researchers have begun to place an emphasis on how educators can encourage and foster a more inclusive concept of parent engagement rather than a more limited operationalization of parent involvement. As an example, current school practice in some states in the U.S., such as Colorado's 'School Accountability Committees' in accordance with the Education Accountability Act of 2009 (S.B. 09-163) (Colorado Department of Education, 2013), requires schools to have increased parental input through multiple opportunities for leadership and focused through focused conversations on family engagement. Further, the state's accountability handbook includes recommendations about diverse representation in its membership to curb the typical effects of disproportionate parent representation.

"To the extent practicable, the local school board must ensure that the parents who are appointed reflect the student populations that are significantly represented within the district. Such student populations might include, for example, students who are members of non-Caucasian races, students who are eligible for free or reduced-cost lunch, students whose dominant language is not English, students who are migrant children, students who are identified as children with disabilities and students who are identified as gifted children" (CDE, 2013, p. 11).

Along with an increased focus on family engagement, the definition of parental involvement has been expanded to recognize changes in family structures; for example, that more students are being cared for by grandparents, extended family members, or other caregivers. The research and discussion around this topic has therefore become more inclusive and has resulted in the development of the term "family engagement" or "family, school, and community partnering" (Colorado Department of Education, 2015). Additionally, the definition of family involvement and "partnering" has expanded from Epstein's seminal model of parent involvement, which included parenting, communicating with teachers, volunteering at the school, learning at home, decisionmaking, and collaborating with the community (Epstein, Coates, Salinas, Sanders, \& Simon, 1997), to include beliefs about families' strengths, intentional relationships, and inclusive community practices.

As an example of this shift from parent involvement to family engagement, the Flamboyan Foundation (2011) developed a model that is inclusive of culturally responsive ways to incorporate family engagement and allows schools and teachers to rate themselves using a rubric that examines cultural competence with diverse families. The rubric allows teachers to rate themselves in areas such as "the teacher is culturally competent and sensitive" and "the teacher is aware of families" cultures, specifically the cultural norms for interacting with teachers and school. The teacher uses this knowledge to reach out to families in culturally respectful ways." (Flamboyan Foundation, n.d., p. 1). As the focus moves from parental involvement to family engagement, many educators continue to search for ways in which they can be more culturally responsive to the students, parents, and families that they serve and to look for ways to better conceptualize and operationalize their engagement with parents from underrepresented groups, such as immigrant parents.

Educational researchers have also broadened the idea of culturally responsive family engagement practices from a one-time event or engagement opportunity within the classroom setting to a more comprehensive strategy that incorporates a family's culture and knowledge. Moll (1992) provides a conceptual model that can help educators foster culturally responsive family 
engagement in which he encourages teachers to look for the "funds of knowledge" held by the families served in schools (p. 21). Funds of knowledge are the resources students and their families possess that often go unnoticed, unobserved, or underutilized by teachers, but can also make great contributions to the academic learning process available to underserved students in public school settings. Moll's research with funds of knowledge include the assumption, "that the educational process can be greatly enhanced when teachers learn about their students' everyday lives" (González, Moll \& Amanti, 2005, p. 6). Nearly 20 years after creating the conceptual model, Moll (2010) reiterates, "For so-called minority children, especially in the contemporary social context, educational resources and opportunities must include integrating their language and cultural experiences into the social and intellectual fabric of schools, much as these have always been seamlessly integrated into the education of privileged White children" (p. 454).

\section{Avoiding Deficit Thinking in Family Engagement}

More recently, scholars have noted the ways Latina/o parents have, in fact, been involved in their children's education, and how educators in schools might build on the strengths that these parents bring to school communities. This change in focus to the strengths of Latina/o parents and recognition of their funds of knowledge requires a shift away from deficit thinking, or blaming students and families for what is perceived and labeled as their inherent deficits, to a focus on internal strengths of families (Gabriel, Martinez \& Obiakor, 2016; Gorski, 2013; Valencia, 2010). A meta-analysis of family involvement studies highlights that the past focus on families' deficits has hindered the relationship building and understanding between teachers and the students and families they serve in family involvement efforts by schools (Guerra \& Nelson, 2013). In fact, Guerra \& Nelson (2013) found that deficit-based thinking leads culturally, linguistically, and economically diverse parents to eventually feel that it is they themselves or their parenting skills that are the problem in schools. For example, when schools offer parenting classes for parents of color and non-White parents, the message parents of color receive is that they are "lacking" (Lawrence-Lightfoot, 2004), and that the school believes that the parents are to be taught or fixed (Daniel-White, 2002).

In response to the growing body of research that examines the strengths of Latina/o parents and their funds of knowledges, this article describes the use of a successful culturally responsive family engagement strategy that goes beyond the simplistic and deficit-based idea of offering a parenting class at school that seeks to teach parents basic parenting skills, presuming they do not have any of the right skills. The creation and implementation of a Photovoice class for a group of Spanish-speaking immigrant parents in this study was one viable way to begin to validate and honor the cultural background, home language, and immigrant experience of parent participants and to provide opportunities for these parents to share their perspectives and experiences with their children's education with educators in the schools and with members of the larger community within which they live. Additionally, while there is an expanding body of literature related to funds of knowledge, there is a gap in the literature related to the use of Photovoice with immigrant populations. This study offers an additional example of culturally responsive family engagement strategies that practitioners and other educators can potentially use in schools when working with students and their families, especially when the students and parents come from immigrant backgrounds.

\section{Methods}


The qualitative study was conducted during the 2012-2013 academic school year in a preschool-grade twelve (PK-12) school district in the Mountain region of the U.S., named here as the Mountain View School District (MVSD). Over the past decade, MVSD ${ }^{i}$ has seen consistent growth in its enrollment of immigrant students. At the time of the study, district officials reported serving approximately 358 immigrant students located throughout nearly every one of the 50 schools in the large, urban school district. While the immigrant students and families enrolled in the district come from countries around the world and speak over seventy languages, the majority come from Spanish-speaking countries. Despite this growing enrollment of immigrant students, very little data existed within the district on the cultural backgrounds of immigrant students and the families themselves, particularly regarding their resettlement into the MVSD and their specific academic, social, and linguistic needs.

The study was created to provide teachers, counselors, administrators, and support staff in MVSD schools with information about immigrant students and their families enrolled within the district. In our full qualitative study, students between third and twelfth grades were participants as well as the family members reported in this article. The research questions for the portion of the study reported in this article are:

1. What are the gifts and strengths that members of Spanish-speaking immigrant families bring to schools in the district?

2. What do Spanish-speaking immigrant parents expect from their children as students?

3. How have our schools treated parents of immigrant students?

4. When given an opportunity, what would Spanish-speaking immigrant families tell our staff about their experiences in our schools and their needs for further support?

Participants were invited from a sample of the schools within the district with the highest number of identified immigrant students. Students' parents and family members were then invited to participate in an evening Photovoice class at a local middle school. Data for this study were gathered through field notes, video transcripts of classes with parent participants, Photovoice posts that included photographs and text, and interviews. By bringing parents together to learn about digital photography and to reflect and write about the photos they took via this project, parents were provided opportunities to share their personal histories and stories of being immigrants in the community of study.

Choosing a culturally responsive method that invited families to share their own stories and backgrounds of their move to the MVSD was critical to the success of the project because of the authors' clear understanding of the implications of the cultural gap between predominantly White teachers in a school district serving a population of approximately $18 \%$ Latina/o students. Photovoice was the chosen method for the project because it seeks to engage participants as coresearchers, teachers, and agents of social change (Blackman \& Fairey, 2007; Wilson, Dasho, Martin, Wallerstein, Wang, \& Minkler, 2007). The authors did not want the participants to feel viewed only as study participants, but rather to consider themselves as co-researchers who were acknowledged and affirmed by educators within their school community and to use the project as a means by which to encourage strong relationship building and continued family engagement with their local school communities.

\section{Meeting the Immigrant Families}


In this section, we describe the process, including information about the context and participants, implemented to access and meet immigrant families as participants in the study.

The project began with a pilot study that included the English Language Acquisition (ELA) family liaisons, cultural mediators ${ }^{\mathrm{ii}}$, equity and diversity coordinator, and the university research team members. Next, students at three schools spanning third to twelfth grades were recruited and participated at their respective site. Principals and assistant principals at each school also provided administrative leadership and logistical support to the project for the initial sessions of the project at each school. In this article, we describe one part of the full qualitative study previously mentioned, which included six Spanish speaking parents who took part in a five-week Photovoice class offered by two of the school ELA family liaisons and members of the research team. The two liaisons used flyers and phone calls to invite Spanish-speaking parents they knew from two participating schools to participate in the class for five evening sessions. All parents who accepted the invitation initially attended an informational meeting and then completed a consent form to participate.

The research team created and conducted workshop sessions with the Spanish-speaking immigrant parents to better understand the experiences of their family within the district and their aspirational hopes for their children. All parents attended five two-hour sessions in which they analyzed visual images, discussed principles of photography and design, took their own photographs of important images within their own lives, and began to write personal narrative text to accompany their photographs. During these weekly meetings, project facilitators sought to create a welcoming environment that allowed Spanish-speaking immigrant parents the opportunity to share their experiences in and out of school openly and talk with one another about their cultural beliefs about family, what they expect from their children in schools, their experiences in schools, and what they would like educators to know about their families. Once parent participants felt comfortable taking photographs and writing about their personal experiences and stories, workshop facilitators asked parents to create and design their own Photovoice posters.

All parents spoke English as a second language, with Spanish being their native language. To support their home language, facilitators gave parents the choice of what language to write in for the creation of their individual Photovoice posters. All parents chose to write their posters in Spanish and indicated which photographs they wanted included in their posters. Once the drafts of the posters were completed, project facilitators and staff within the district worked to translate the original text, so that the final posters were presented in both Spanish and English. Facilitators then revised the posters one additional time with the participants to make sure to capture the spirit and intent that participants wanted to share. After all revisions were made, facilitators conducted final member checks by interviewing the participants about their posters. The interviews, conducted in Spanish, were recorded and later transcribed. In this way, parents had multiple opportunities to express their ideas about their project in even greater detail with project facilitators, to elaborate on themes they introduced in their photos, and to delete any misunderstood concepts or themes. Parent posters were eventually displayed as part of a month-long public exhibition at a gallery space in the downtown area of the local community. In their feedback on the project, parents expressed pride in their individual Photovoice posters as well as the collective work completed by their fellow parents from the Spanish-speaking community within the school district.

\section{Data Analysis}

Each parent participant in the project was asked to take photographs and to write text to address each of the following four main headings: the strengths of our family, expectations for our 
children in school, my own experience in schools as a parent, and what I want educators to know. Researchers used thematic analysis to identify main themes raised by parents in their Photovoice posters (Boyatzis, 1998; Braun \& Clarke, 2006; Miles \& Huberman, 1994). While some participants' responses fit naturally under each heading, the researchers also found themes across headings that were connected to one another. Additionally, one of the members of the research team is a member of the Latina/o community and is bilingual. She went back to the Spanishlanguage transcripts and text to search for cultural meaning behind the English translations. A critical perspective is needed to find the themes that may otherwise go unseen and to fully develop these themes (Gibson \& Brown, 2009), particularly when seeking understanding of communities of color and immigrant families.

\section{Knowing the Families: The Findings}

This section will focus on what we learned about Spanish-speaking immigrant families based on their photographs, stories, and Photovoice posters. The findings of this study are described under each of the headings described by the families.

\section{Strengths of Family}

While the parents described individual experiences, the findings developed into shared collective stories of how they experienced school and life as a family unit rather than as individuals (Trumbull, Rothstein-Fisch, Greenfield, \& Quiroz, 2001) and underscored the many strengths their family had and could offer to educators at their children's schools. For example, parents described their family's strengths as being loving toward each other and intentionally making time to spend together. The participants in this study placed emphasis on describing the strengths of families related to concepts of love and union within their family structure and organization. For example, Marcela stated "They [my two children and husband] are my three reasons for living." Another example includes Aracely's description, "My children and my husband are my life." This finding echoes Kulago's (2016) indigenous study findings related to family engagement, defined as the Diné culture's "enduring principle of $k$ 'é in which the relationships between family and others stem from feelings of love and loyalty" (p. 4). Both are non-traditional, non-Western ways of thinking about family engagement that we can arrive at when culturally responsive family engagement is utilized.

Additionally, parents wrote about making intentional efforts to schedule time together and that special family events were always a priority. Marcela writes "The moments of being together with the family are so important and unforgettable, whether they are good or bad" and "the strength of the family is union." Often Spanish-speaking parents are excluded from the educational process in U.S. public schools due to language or cultural misunderstandings, but it became clear during the project that the deep love and closeness demonstrated by the participants in this study fuels their hopes and dreams for being actively involved in their children's education. Parent participants never spoke about family from an individual perspective, but about how the collective nature of existing and focusing on being together as families was seen by them as a strength. How might schools build on parents' conceptions of collective strength and union when considering how to build more effective family-school partnerships?

\section{Families' Expectations for Their Children as Students}


Parents in the study described having high and clear expectations for their children to do well in school. Parents reported that they were ready to provide support for their children and hoped that their educational experiences in school would lead them to successful career paths.

Parents shared that they specifically want their children to take advantage of the opportunity to be in school. For example, Rogelio describes his hope that his children "learn everything possible, so they can grow to be people who do good and can seize opportunities." This finding mirrors prior research on Latina/o parent involvement (Guerra \& Nelson, 2013; Valdés, 1996) that demonstrates the importance of high parental expectations within Latina/o families.

Some parents described their availability as volunteers to support their children at home as well as at school. Carolina described her support as "I love the schools and volunteer when I can." Carolina's self-confidence and desire to see her child succeed in school is an important point for teachers to acknowledge and understand. Teachers and other support staff in schools need to create school communities where parents feel welcome and to provide a variety of opportunities for Spanish-speaking parents to be able to volunteer in the classroom and school. It behooves teachers to build relationships and trust with parents and connect these same parents to successful volunteer opportunities so they will feel welcome to volunteer and provide their time and energy to the school. Carolina has volunteered every year of her child's schooling in a bilingual school where many staff members speak Spanish and where communication between teachers and immigrant parents was highly encouraged and facilitated.

Finally, parents in the study expressed clearly their hope that their child's education would lead to a professional career. For example, Esmeralda said "Our children also want to be someone important like a teacher, an engineer, a veterinarian, or a fireman." While school officials often question the legitimacy of the background knowledge and expectations of immigrant families due to their family income and lack of formal education, the parents in this study eloquently stated that they too hope for viable career opportunities for their children.

The ways in which parents stated their expectations for their children in their posters debunked myths that exist in PK-12 settings about immigrant families. The family members' voices give critical inside information about the ways they are "pulling for" their children, advocating for them at home, and using their own personal stories to motivate their children to take advantage of formal education, to support their children, to encourage learning, and to hope that the sacrifices of today will lead to a career in the future for their children.

\section{Families' Experiences with Schools in the U.S.}

Parents described their mostly positive personal experiences with teachers or the school their students attend. However, Rosa believes that language can often be a barrier for immigrant families in U.S. schools and stated, "Up until now I feel that the language has not permitted me to have open communication with teachers." She went on to share that "I've had to move my sevenyear old daughter...to a different school twice. Finally, I was able to accommodate her and myself in a school where we all understand each other." Several parents noted their appreciation for the variety of opportunities and support schools offer their children. Esmeralda, for example, described multiple supports made available to her and her family by teachers and support staff at her children's schools including "English Language Acquisition classes, extra activities after school, and that schools offer options for paying for activities and school meals."

As with other positive experiences in schools, Rogelio described the schools as "safe and sophisticated." Although all of the parent participants had limited access to formal schooling when they were growing up, they view the schools in the school district where their children were 
registered in as filled with educational opportunities and access that they highly support. This study then offers a unique insight into how immigrant families view the schools their children attend in a positive light and as wonderful learning environments for their children. Parent participants in the project placed high value on the opportunity their children have to attend free public school and work hard to motivate their children to appreciate and take advantage of opportunities. This finding echoes a previous educational study stating that many immigrant parents have risked their lives to come to the United States to offer their children better educational opportunities and work to inculcate the importance of education in their children (Valdés, 1996).

\section{What We want Educators to Know}

Families in this study want educators to understand their family's ethnic culture and the fact that they want to be involved in their child's education. For example, parents expressed the idea that they are working to educate their children at home about their cultural beliefs, values, and traditions while the children attend school to learn academics. They also want educators to know about their family's value for their culture. Rosa wrote "I would like them [the teachers] to know that we have a different culture than they do here and that we practice it at home." Schools do not often talk about race, ethnicity, and student's cultural influences at school, so it is important to know that families want teachers in schools and their own children to begin to have these conversations about home culture and language. Marcela also describes her perspective on this topic, "For me as a mother it's very important that my children conserve our culture and traditions." She also shared that "We are open to helping in any way we can to further develop our children's cultural development" and "I think the ability to speak two languages is a privilege not just for my children, but for everyone." Beyond their cultural background, parent participants also wanted teachers to value them and know that they are here to support their children. Luis said he and his wife "would like teachers to know that we came to this country to better ourselves and to help our children get ahead." The plan for their child's future and their goals for their children demonstrate their high expectations. Parent responses throughout the project support research that the highest impact of a child's success in school is parental expectations (Scott Stein \& Thorkildsen, 1999; Jeynes, 2005).

\section{Discussion: The Importance of Affirming Families}

Educators are often in support of having families from all cultural backgrounds engaged in their children's schools, yet due to the cultural gap between educational leaders and the families they serve, the strategies chosen are not always culturally responsive or implemented in an affirming way (Garcia, 2014; Guerra \& Nelson, 2013; Kulago, 2016). To address their school demographics, educators should continue to rethink the way schools conceptualize and structure opportunities and family involvement efforts. What we have learned in this study is that Latina/o, particularly Spanish-speaking immigrant, families have unique cultural gifts and assets that teachers and other educators in schools can build on: a strong love and commitment to their family; high expectations for student success; perseverance in their pursuit of formal schooling for their children despite the cultural and language gaps families face; and their desire to have their cultural values honored by educators.

To respond in an affirming way to what we have learned, educators must re-think the parental involvement strategies that have been used in the past that are historically individualistic and the prevalent use of one-way communication methods to inform families of their children's behavioral and academic performance, such as through teacher-led parent-teacher conferences 
(Cooper, et al., 2010; Henderson \& Mapp, 2009). Many schools are realizing the need to look beyond these traditional methods of parent involvement because they are not effective in reaching the changing demographic of schools, particularly immigrant families who come from a collective cultural background. There is a growing and urgent need to look beyond the individualistic model of parent involvement toward a collectivist model to increase participation from culturally and linguistically diverse family members and to honor the participation and involvement of parent groups, which has historically gone unrecognized (Guerra \& Nelson, 2013). This need requires educational leaders who implement family engagement efforts to rethink old paradigms including deficit thinking and power dynamics between school staff and families.

Family engagement should also include a linguistically and culturally responsive foundation. Analysis of the Photovoice posters and interviews in this research study unearthed a variety of cross-cultural strategies that teachers and other school leaders can all learn from. Three strategies are offered as part of the discussion section of this article.

\section{Bilingual Staff}

School administration should recruit and hire bilingual and bicultural school personnel to be bridges for communication between home and school and to address the cultural mismatch found in public schools today (Colorado Department of Education, 2014). During the project, we could not have come to a place of meeting and knowing Spanish-speaking immigrant families' perspectives and experiences without having bilingual personnel involved in this research project. Through speaking the same language as the parents in the study and by having easy access to interpretation when needed, we learned that parents who cannot communicate with the school feel that they do not have access to the school. As Rosa stated, "Up until now I feel that the language has not permitted me to have open communication with teachers." This experience ended up in multiple moves and transitions between schools for one of her children as she searched for a school with teachers and principals with whom she could better communicate. These multiple moves from school to school impacted her child's access to instructional time.

Since People of Color have stories that are often unlikely known by those from the dominant culture (Delgado \& Stefancic, 2001), recruiting educators who know and can effectively communicate with culturally and linguistically diverse families can be one useful way in educating teachers from the dominant group about the impacts of culture in a classroom. Bilingual and bicultural individuals should work at the front office of a school and as teachers, counselors, and administrators in schools. Having bilingual personnel working in all facets of a building allows for communication to take place in a variety of ways and instances. It encourages and builds ongoing collaborative relationships between parents, teachers, and bilingual staff versus the typical practice of only calling in an interpreter when communication becomes critical or urgent. This basic step of increasing the number of bilingual and bicultural staff in a school can increase our opportunities to meet and know the families we serve, so we can work toward affirming who they are and by placing ourselves in a better position to address and meet their educational needs.

\section{Honor Home Language}

When offering family engagement opportunities, educators need to create opportunities for parents to attend a class or meeting in their home language. Encouraging parents to speak in their native language allows for a more authentic and transparent level of participation that can often be hindered when English only is required. Schools often debate how to provide language support for school-based meetings, but when we ask parents what they prefer, they will let us know. Creating 
linguistic supports such as interpreting and having bilingual staff creates a more comfortable environment for attendees, and we can therefore increase our support for immigrant parents and their children. Doing so connects directly to the funds of knowledge research by bringing the family's home language into the framework for the family engagement (González, et al., 2005; Moll, 2010).

\section{Provide Opportunities to get to Know Families}

Educators need to make time and space for family engagement that is not just focused on the business of school. In this study, we started with a timeline suggested by the research team that the critical work was to get to the final projects: the posters. Yet, we also knew that childcare and a meal would help create accessibility for families to attend. Then, we welcomed the finding that during the shared meal time, families began to reach out to each other and to learn more about where they were from and who their children were. Because of the community spirit built during these meals before the classes, parents began to support each other in stronger ways during the workshops, including offering words of encouragement regarding difficult issues with a child, or assisting each with the creation of their posters. The families became a close-knit group empowered by each other during their sharing and their learning about their individual and collective experiences immigrating to the United States and raising children in the community of the study. This outcome models what Garcia (2014) recommended in his study related to indigenous family engagement referred to as "creating spaces for dialogue: a sense of ownership and validation" (p. 71).

\section{Conclusion}

The themes uncovered by this community-based project support much of the research on the funds of knowledge of immigrant parents and how these parents support their children and schools in both visible and invisible ways (Moll, 1992, 2010) and the usefulness of implementing culturally responsive pedagogy into family engagement efforts. Though they are often hidden members of school communities, immigrant parents have very important contributions to make to the success of a school, and finding a culturally responsive approach to family engagement is important to the success of these efforts. When educational leaders create time and space for families to share about themselves and their experiences in schools in their home language, they can discover the different ways in which Spanish-speaking immigrant parents value education and wish to support the teachers and other educators that work with their children.

By affirming the resources and support immigrant parents can bring to our schools and classrooms, educators can begin to recognize how immigrant parents have often overcome insurmountable challenges to offer their children what they deem to be a prestigious education. Rosa put it this way, "As parents we work to give them an education, which is the best inheritance we could ever give our daughter." Parents want their children to be educated, so they can have a career and give back to their communities. As Esmeralda described, "We would like teachers to know that we came to this country to better ourselves and to help our children get ahead. Our children also want to be someone important like a teacher, an engineer, a veterinarian, or a fireman." This authentic response from a parent during our project debunks many deficit stereotypes that exist about why immigrants have come to the United States. Hearing authentic stories from the members of marginalized communities is particularly important as we live in a time and place in the U.S. where myths and lies are spread about immigrant populations. Allowing 
our White staff to hear from immigrant parents their true stories can be a way to address the "culture clash" (Viadero, 1996) that exists between White teachers and the culturally and linguistically diverse students they serve.

The promotion of ongoing conversations with parents can help educators not fall into an equity trap of deficit thinking where blaming students and parents becomes the norm (Gorski, 2013; Valencia, 2010). Instead, we need to challenge educators in schools to begin to think crossculturally to comprehend, examine, and address concerns parents can raise about racism, immigration status, and student achievement. "Clearly race and income are connected to school experiences, access, and opportunity, and consequently to student achievement, yet in traditional education circles there has been a tendency to see that as evidence of the difficulties inherent in educating these children, rather than the flaws of the educational practice itself' (Theoharis, 2009, p. 6). By utilizing an equity pedagogy, avoiding equity traps such as deficit thinking (McKenzie $\&$ Scheurich, 2004), and implementing culturally responsive teaching and culturally responsive educational practices such family engagement (Garcia, 2014; Guerra \& Nelson, 2013; Kulago, 2016; Villegas \& Lucas, 2002), schools can begin to provide supportive and positive opportunities and access for immigrant families in schools.

Photovoice projects are an example of an important contribution to the existing research on involvement of immigrant parents. The projects can serve as a vehicle of empowerment to uncover the funds of knowledge present in homes of immigrant families and disrupt deficit thinking that further marginalizes immigrant students and families from schools. We hope that this article provides educators and educational researchers specific strategies to develop and strengthen home-school connections through culturally responsive collaborative efforts. Research projects and classes that use the Photovoice method is one way to help immigrant parents and other parents whose voices have been either silenced or marginalized at school sites. By finding ways to amplify the voices of immigrant parents through photographs and text, educational leaders can learn more about the diversity of children and their parents enrolled in their schools.

The research in this study highlights the need for teachers, administrators, and other school leaders to re-think parental outreach and home-school communication and to move away from including parents only on a need-to-know basis, but to move toward affirmation and collective empowerment in our family partnering. While "School culture is relatively consistent across the United States and reflects the individualistic values of the dominant, European American culture" (Rothstein-Fisch \& Trumbull, 2008, p. xiii), the cultural gap does not have to limit success. In fact, "many Latino parents constantly communicate the importance of education to their children through words and actions" (Guerra \& Nelson, 2013, p. 436). We need to be willing to find culturally responsive ways to meet and know our immigrant families so we can respond in affirming ways. The Photovoice Project in the Mountain Valley School District in Colorado demonstrates one more way in which educators can begin to focus on and highlight the hopes and aspirations of immigrant parents for their children in public school in the U.S. As a collaborative partnership, Photovoice projects can invite immigrant families to the table to be co-creators of the knowledge that we need to begin to attend to in more thoughtful, conscientious, and deliberate ways in our leadership roles as teachers and educators in public schools. Taking time to re-think current parental involvement strategies through a culturally responsive lens will create opportunities to meet, know, and affirm immigrant families to ensure we serve our families better. 
Meeting, Knowing, and Affirming Spanish-speaking Immigrant Families

\section{References}

Blackman, A., \& Fairey, T. (2007). The PhotoVoice manual: A guide to designing and running participatory photography projects. London, UK: PhotoVoice. Retrieved from https://photovoice.org/wp-content/uploads/2014/09/PV_Manual.pdf

Boyatzis, R. E. (1998). Transforming qualitative information: Thematic analysis and code development. Thousand Oaks, CA: SAGE Publications.

Braun, V., \& Clarke, V. (2006). Using thematic analysis in psychology. Qualitative Research in Psychology, 3(2), 77-101.

Colorado Department of Education (2014). District accountability handbook version 4.1. Retrieved from http://www.cde.state.co.us/accountability/district_accountability_handbook2014

Colorado Department of Education. (2015). Multi-Tiered Family, School, and Community Partnering. Retrieved from https://www.cde.state.co.us/mtss/fscp

Colorado Department of Education. (2013). District Accountability Committee Handbook Version 3.0. Retrieved from http://www.cde.state.co.us/accountability/districtaccountabilityhandbook

Cooper, C. W., Riehl, C. J., \& Hasan, L. (2010). Leading and learning with diverse families in schools: Critical epistemology amid communities of practice. Journal of School Leadership, 20(6), 758-788.

Cross, T. L., Bazron, B. J., Dennis, K. W., \& Isaacs, M. R. (1989). Toward a culturally competent system of care: A monograph on effective services for minority children who are severely emotionally disturbed. Washington, DC: Georgetown University Child Development Program, Child and Adolescent Service System Program.

Daniel-White, K. (2002). Reassessing Parental Involvement: Involving Language Minority Parents in School Work at Home. Working Papers in Educational Linguistics, 18(1), 2949. Retrieved from http://repository.upenn.edu/wpel/vol18/iss1/2

Davis, B. M. (2007). How to teach students who don't look like you: Culturally relevant teaching strategies. Thousand Oaks, CA: Corwin Press.

Delgado, R., \& Stefancic, J. (2001). Critical race theory: An introduction. New York, NY: New York University Press.

El Nasser, H., \& Overberg, P. (2010, August 27). Kindergartners see more Hispanic, Asian students. USA Today. Retrieved from http://usatoday30.usatoday.com/news/nation/census/2010-08-271Akindergarten27_ST_N.htm 
Epstein, J. L., Coates, L., Salinas, K. C., Sanders, M. G., \& Simon, B. S. (1997). School, Family, and Community Partnerships: Your Handbook for Action. Thousand Oaks, CA: Corwin Press.

Flamboyan Foundation. (n.d.). Classroom Family Engagement Rubric. Retrieved from http://www.hfrp.org/var/hfrp/storage/fckeditor/File/file/FINE\%20Newsletter/Winter2011 /FINE-Flamboyan_Rubric.pdf

Flamboyan Foundation. (2011, August 11). School-wide family engagement rubric. Retrieved from http://flamboyanfoundation.org/resources_and_publications/school-widefamilyengagement-rubric/

Gabriel, M. L., Martinez, J., \& Obiakor, F. (2016). Dismantling deficit thinking through teacher preparation. In F. Obiakor, A. Rieger, and A. Rotatori (Eds.), Critical Issues in Preparing Effective Early Child Special Education Teachers for the $21^{\text {st }}$ Century Classroom: Interdisciplinary Perspectives, (pp. 25-36). Charlotte, NC: Information Age Publishing.

Gagne. C., Bowers, A., Russinova, Z., Bloch, P. \& McNamara, S. (2010). Combating Prejudice and Discrimination through Photovoice Empowerment: Leader's Guide.

Garcia, J. (2014). Re-examining indigenous conceptualizations of family and community involvement. Journal of Family Diversity in Education, 1(1), 58-74. Retrieved from file://C:/Users/mgabriel/Downloads/24-125-4-PB\%20(2).pdf

Gay, G. (2010). Culturally responsive teaching: Theory, research, and practice $\left(2^{\text {nd }} E d\right.$.). New York, NY: Teachers College Press.

Gibson, W. J., \& Brown, A. (2009). Working with qualitative data. Thousand Oaks, CA: Sage Publications, Inc.

González, N., Moll, L. C., \& Amanti, C. (2005). Introduction: Theorizing practices. In N. González, L. C. Moll, \& C. Amanti (Eds.), Funds of knowledge: Theorizing practices in households, communities, and classrooms (pp. 1-24). Mahwah, NJ: Lawrence Erlbaum Associates.

Gorski, P. (2013). Reaching and teaching students in poverty: Strategies for erasing the opportunity gap. New York: Teachers College Press.

Guerra, P. L. \& Nelson, S. W. (2013). Latino parent involvement: Seeing what has always been there. Journal of School Leadership, 23(3), 424-455. Retrieved from https://www.researchgate.net/profile/Sarah_Nelson_Baray/publication/283225717_Latin o_parent_involvement_Seeing_what_has_always_been_there/links/5646806608ae45188 0aa6016.pdf 
Meeting, Knowing, and Affirming Spanish-speaking Immigrant Families

Guerrero, A., \& Tinkler, T. (2010). Refugee and Displaced Youth Negotiating Imagined and Lived Identities in a Photography-Based Educational Project in the United States and Colombia. Anthropology \& Education Quarterly, 41(1), 55-74.

Henderson, A. T. \& Mapp, K. L. (2002). A New Wave of Evidence: The Impact of School, Family, and Community Connections on Student Achievement. Austin, TX: Southwest Educational Development Laboratory. Retrieved from http://files.eric.ed.gov/fulltext/ED536946.pdf

Hess, D. J., Lanig, H., \& Vaughan, W. (2007). Educating for equity and social justice: A conceptual model for cultural engagement. Multicultural Perspectives, 9(1), 32-39.

Howard, G. R. (2006). We can't teach what we don't know: White teachers, multiracial schools (2nd Ed.). New York, NY: Teachers College Press, Columbia University.

Jeynes, W. H. (2005). Parental involvement and student achievement: A meta-analysis. Family Involvement Research Digests. Retrieved from http://www.hfrp.org/publicationsresources/browse-our-publications/parental-involvement-and-student-achievement-ameta-analysis?print $=1$

Kulago, H. A. (2016). Activating indigenous knowledge to create supportive educational environments by rethinking family, community, and school partnerships. Journal of Family Diversity in Education, 2(1), 1-20. Retrieved from http://familydiversityeducation.org/index.php/fdec/article/view/76/67

Ladson-Billings, G. (2009). The dreamkeepers: Successful teachers of African American children. San Francisco, CA: John Wiley \& Sons.

Landsman, J., \& Lewis, C. W. (Eds.). (2006). White teachers, diverse classrooms: A guide to building inclusive schools, promoting expectations, and eliminating racism. Sterling, VA: Stylus Publishing.

Lawrence-Lightfoot, S. (2004). Building bridges from school to home. Instructor, 114 (1), 2428.

Lindsey, R., Nuri Robins, K., \& Terrell, R. D. (2003). Cultural proficiency: A manual for school leaders. Thousand Oaks, CA: Corwin Press.

Lindsey, R., Nuri Robins, K., \& Terrell, R. D. (2009). Cultural proficiency: A manual for school leaders, 2nd Ed. Thousand Oaks, CA: Corwin Press.

Lockhart, L. L. \& Danis, F. S. (2010). Domestic violence: Intersectionality and culturally competent practice. New York, NY: Columbia University Press. 
Lockhart, L. L., \& Mitchell, J. (2010). Cultural competence and intersectionality: Emerging frameworks and practical approaches. In L. L. Lockhart \& F. S. Danis (Eds.), Domestic violence: Intersectionality and culturally competent practice (pp. 1-28). New York, NY: Columbia University Press.

McKenzie, K. B., \& Scheurich, J. J. (2004). Equity traps: A useful construct for preparing principals to lead schools that are successful with racially diverse students. Educational Administration Quarterly, 40(5), 601-631. doi:10.1177/0013161X04268839. Retrieved from http://journals.sagepub.com/doi/pdf/10.1177/0013161X04268839

Miles M. B., \& Huberman, A. M. (1994). Qualitative data analysis: An expanded sourcebook (2nd ed.). Thousand Oaks, CA: Sage.

Moll, L. C. (1992). Bilingual classroom studies and community analysis: Some recent trends. Educational Researcher, 21(2), 20-24. Retrieved from http://journals.sagepub.com/doi/pdf/10.3102/0013189X021002020

Moll, L. C. (2010). Mobilizing culture, language, and educational practices: Fulfilling the promises of Mendez and Brown. Educational Researcher, 39(6), 451 -460. doi:10.3102/0013189X10380654. Retrieved from http://journals.sagepub.com/doi/pdf/10.3102/0013189X10380654

National Collaborative on Diversity in the Teaching Force. (2004). Assessment of diversity in America's teaching force: A call to action. Washington, DC. Retrieved from http://www.ate1.org/pubs/uploads/diversityreport.pdf

Rothstein-Fisch, C., \& Trumbull, E. (2008). Managing diverse classrooms: How to build on students' cultural strengths. Alexandria, VA: Association for Supervision and Curriculum Development.

Scott Stein, M. R., \& Thorkildsen, R. J. (1999). Parent involvement in education: Insights and aapplications from the research. Research for the Practitioner Series. Bloomington, IN: Phi Delta Kappa International.

Theoharis, G. (2009). The school leaders our children deserve: Seven keys to equity, social justice, and school reform. New York: Teachers College Press.

Trumbull, E. \& Pacheco, M. (2005). Leading with diversity: Cultural competencies for teacher preparation and professional development. Providence, RI: Brown University and Pacific Resources for Education and Learning. Retrieved from http://www.alliance.brown.edu/pubs/leading_diversity/lwd_entire.pdf

Trumbull, E., Rothstein-Fisch, C., Greenfield, P. M., \& Quiroz, B. (2001). Bridging cultures between home and school: A guide for teachers with a special focus on immigrant Latino families. Mahwah, NJ: Lawrence Erlbaum Associates. 
Meeting, Knowing, and Affirming Spanish-speaking Immigrant Families

Valdés, G. (1996). Con respeto: Bridging the distances between culturally diverse families and schools: An ethnographic portrait. New York, NY: Teachers College, Columbia University.

Valencia, R. R. (2010). Dismantling contemporary deficit thinking: Educational thought and practice. New York: Routledge.

Viadero, D. (1996, April 10). Culture clash. Education Week, 15(29), 39-42.

Villegas, A. M., \& Lucas, T. (2002). Preparing culturally responsive teachers rethinking the curriculum. Journal of Teacher Education, 53(1), 20-32. doi:10.1177/0022487102053001003. Retrieved from http://journals.sagepub.com/doi/pdf/10.1177/0022487102053001003

Wells, M. I. (2000). Beyond cultural competency: A model for individual and institutional cultural development. Journal of Community Health Nursing, 17(4), 189-199.

Wilson, N., Dasho, S., Martin, A. C., Wallerstein, N., Wang, C. C., \& Minkler, M. (2007). Engaging young adolescents in social action through Photovoice: The youth empowerment strategies (YES!) project. The Journal of Early Adolescence, 27(2), 241261. doi: 10.1177/0272431606294834. Retrieved from http://journals.sagepub.com/doi/pdf/10.1177/0272431606294834

\section{Notes}

${ }^{\mathrm{i}}$ All names of places and people have been anonymized.

ii Family liaisons and cultural mediators were employed at each school to work directly with immigrant parents and their teachers. Liaisons and mediators worked in classrooms at each school to provide language support to students, help with communication with parents, and serve as translators during the school day and at after-school meetings. 